\title{
GUIÓN PARA PENSAR LA METÁFORA
}

Julián Santos Guerrero

Que un laberinto encierre sus propias salidas, que un heliotropo gire sin cesar cara al sol y encuentre su fin abismado, petrificado, entre la doble lámina celulósica del libro. Que las metáforas se multipliquen sin fin, metáfora del fin, fin de la metáfora, fin sin más... Todo ello no agotaría los textos trazados, trenzados, relevados y reelevados, de Jacques Derrida acerca de la metáfora. Se trataría allí de un relevo y de una reelevación, de una retirada y de la duplicación repetitiva de un trazo, de una reescritura excesiva y de una inscripción que anuncia el fin, imposible e inminente a la vez, de la metáfora; todo ello al hilo de un cierto tono, con un tono, sobre y desde un tono, apocalíptico.

El guión (-)

¿Qué se releva en "La mitología blanca"? la metáfora: «La metafísica - relevo de la metáfora». Así se encabeza el último epigrafe de aquel artículo, uno de los dos escritos en los que Derrida aborda en exclusiva el tema de la metáfora. El trazo que contiene el enunciado, el guión intermedio, pone una cierta dificultad en ese juego de transcripción más o menos mecánica de lector desatento que habitualmente pasa por alto algunas marcas tipográficas, ciertos lugares extraños en la topografía de un texto, espacios de conflicto que a nosotros ya no nos debieran pasar desapercibidos y menos a partir de la intención, ahora manifiesta,

\footnotetext{
1 Los dos artículos de Jacques Derrida sobre la metsfora y a los que nos vamos a referir continuamente en este escrito son: "Io

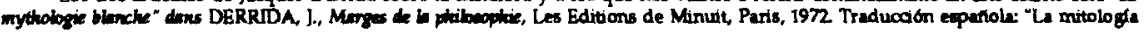

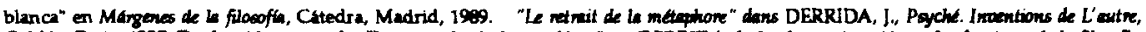

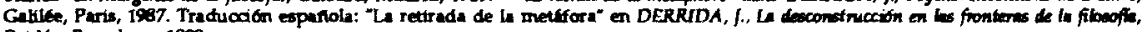
Paidos, Burcelona 1999.
}

Éndoxa: Series Filosofficas, $n^{\circ}$ 8, 1997, UNED, Madrid: Julián Santos Guerrero: Guión para pensar la metáfora. pp. 2177-233. 
de guiarnos por esos lugares, de tener como guión para pensar y pasar por la metáfora, afirmaciones conflictivas de J. Derrida respecto a lo trópico y a la filosofía; de tratar por nuestra parte de leer así ciertos gestos escriturales suyos (un guión por ejemplo) como las marcas de una cuidadosa economía metafórica, como los pasos, las guías, que posibilitan la aplicación de un movimiento al pensamiento de un viejo tema².

¿Qué se releva en "La mitología blanca"? preguntábamos. El guión, ese pequeño trazo que corta la frase, parece decir: la metafísica es relevo de la metáfora. De alguna manera, el trazo suprime y "suple" la conjugación y escritura del verbo "ser", dejaría leer el verbo ausente en el intervalo de su suplencia tipográfica -ya esa sustitución y "suplemento de la cópula" ${ }^{13}$ sería sintomática; el "relevo" del verbo ser por un trazo bien podría darnos ciertas pistas, no obstante dejamos por ahora este síntoma para interesarnos en otra complicación-. La frase con su guión vendría a decir, al menos en principio, que la metafísica se establece, pues, como relevo de la metáfora, esto es: en un determinado ámbito (lugar original o conclusivo, depende por donde se mire), allí donde antes había metáfora, ahora, por medio de un paso de sustitución, de sublimación o de relevo (Aufhebung hegeliana) hay idea, metafísica. Parece que el guión iguala los dos términos de la frase cortada por él haciéndose equivalente a un doble trazo, a un retrazo (=). Así las cosas, el primer extremo de la enunciación debe asumir también la ambigüedad implícita en el segundo (el genitivo puede leerse como subjetivo u objetivo) y decir ahora que la metafísica vendría a ser un relevo implícito en la metáfora, uno de sus relevos, un paso más en el interior de una metafórica determinada y determinante. Si la metáfora implica una transferencia (meta-fora, llevar más allá, traslado, sobrepasar), una economia que se releva de un sentido a otro, un tráfico continuo de intercambio de sentidos, de una posta a otra (desde un sentido llamado

2 La metifora es un tema tan viejo como la muerte. Este artículo explota los vinculos de vecindad entre una y ota.
3 Remitimos a "El suplemento de la copula. La filosofla ante la lingǘstica", en DERRIDA, J., Margenes de la fibeofin, op. cit. 1999. 
"propio" a otro dicho "metafórico") "envío" y "carta postal", entonces la metafísica sería otro relevo más: lo "propio", y así lo más propiamente metafísico, estaría ahora en el lugar trocado, en el puesto de un sentido metafórico que exigiría a su vez el relevo por otro sentido metafórico, llevando de esta manera la ley del transporte a su exceso sin límites. La metafísica permanece, pues, en el interior de la metáfora.

En cualquiera de los sentidos que le hayamos dado a la complicada tipografía del título, la metáfora, bien por un relevo definitivo y cortante, o bien por generalización de su continuo movimiento de relevo, "construye indefinidamente su propio final". Esto es lo que Derrida llama la autodestrucción de la metáfora en su doble trayecto:

"Esta autodestrucción siempre habrá podido seguir dos trayectos que son casi tangentes $y$, sin embargo, diferentes, se repiten, se imitan, y se separan según ciertas leyes. Uno de estos trayectos sigue la línea de una resistencia a la diseminación de lo metafórico en una sintáctica que comporta en alguna parte e inicialmente una pérdida irreductible del sentido: es el relevo metafísico de la metáfora en el sentido propio del ser. La generalización de la metáfora puede significar esta parousia. La metáfora es entonces comprendida por la metafísica como aquello que debe retirarse en el horizonte o en el fondo propio y acabar por reencontrar alli el origen de su verdad. El giro del sol se interpreta entonces como círculo especular, retorno a sí sin pérdida de sentido, sin gasto irreversible. (...)

La otra auto-destrucción de la metáfora se parecería hasta el punto de confundirse con la filosófica. Pasaría, pues, esta vez, atravesando y doblando la primera, por un suplemento de resistencia sintáctica, por todo lo que (por ejemplo, en la lingüistica moderna) desbarata la oposición de lo semántico y lo sintáctico y sobre todo la jerarquía filosófica que somete esto a aquello. Esta auto-destrucción tendría todavía la forma de una generalización, pero esta vez no se trataria de extender y de confirmar un filosofe- 
ma; más bien, desplegándolo sin límite, de arrancarle los lindes de propiedad. $Y$ por consiguiente de hacer saltar la oposición tranquilizadora de lo metafórico y de lo propio en la que lo uno y lo otro no hacian más que reflejarse y remitirse su resplandor. ${ }^{4}$

La lectura de aquel guión se complica más aún cuando vemos en él una línea direccional, la guía de un movimiento que nos lleva de la metafísica al relevo de la metáfora y, como cualquier puente de comunicación tendido entre dos extremos, también a la inversa. Algo así como una señal de doble dirección que las separara y, en un mismo trazo, las pusiera en contacto, como si cada una de ellas no fuera otra cosa que los límites de ese guión, finales de trayecto de una misma vía. De hecho, hace en ello hincapié Derrida hasta la repetición, no pueden pensarse la una sin la otra. El deseo de una metafórica original a la que pudiera reducirse toda la terminología metafísica contendría ya, a su vez, el entramado del que la propia metafísica surge y, con él, toda su tupida red de oposiciones (entre lo propio y lo impropio, entre el interior y el exterior, entre el origen y lo originado...) - «La metáfora sigue siendo por todos sus rasgos esenciales, un filosofema clásico, un concepto metafísico", y más adelante, de una manera más "metafórica": «Cada vez que hay una metáfora hay, sin duda, un sol en alguna parte; pero cada vez que hay sol, ha comenzado la metáfora ${ }^{5}$ - Cualquier retórica que defina la metáfora se encuentra interior a ese complejo, también él metafórico, que ha dado lugar al sistema de oposiciones propiamente metafísico: la metáfora es interior a la metafísica.

\section{La complicación del guión}

El cruce tan complejo que tiene lugar en el guión no sólo expresa la densidad excesiva de nociones que vierten sobre él, sino que él mismo complica, trenza y anuda los caminos que le llegan,

4 DERRDDA, J., Migigeses de lo fibooft, op. dt pp.307-308 y 310 respectivamente.

5

Mingones de is fiboofin, op. ot pp. 259 y 291 respectivamente. 
posibilitando la mutua penetración de los términos. Entresacamos de los dos artículos de Derrida las siguientes complicaciones:

1.- Exterior-Interior:

Por una parte la metáfora es exterior al discurso metafísico que sólo la emplea con fines propedéuticos o económicos, como herramienta que debe ser desechada una vez terminado el proceso. Por otra, la metáfora permanece interior a la metafísica por razones intrínsecas a su discurso, como recorrido de lo sensible a lo inteligible. De aquí que, como han pensado distintos autores de los que "La mitología blanca" da cuenta debida, las nociones metafísicas fundamentales puedan ser derivadas genealógicamente de un conjunto bien limitado de metáforas del mundo sensible. No obstante, como ya se ha dicho, esta retórica que pretendería contener la metafísica sería, a su vez, interior a un sistema de oposiciones que en sí es ya metafísico.

De todo este cuadro puede seguirse que los dominios de la metáfora y la metafísica se contienen mutuamente, esto es, componen una estructura laberíntica cuyas salidas le son interiores. 2.- Final-infinito:

Cada uno de los extremos del guión que separa metafísica y metáfora definiría a una como límite de la otra y a la inversa. La metafísica constituiría el relevo final de la metáfora. Usada ésta por el camino (círculo del sol) queda finalmente asumida y cancelada, superada en su límite. La metáfora generalizada representa, por su lado, el final de lo propio.

Llegados a este punto, nos interesa observar los desplazamientos que la lectura de Derrida provoca en el texto de Heidegger. La cuestión merece un cierto detenimiento.

Aquella afirmación heideggeriana: «Sólo en el interior de la metafísica se da lo metafórico ${ }^{6}$, encierra un alto grado de complicación. Enunciada aún como si no hubiera más que un solo concepto de metáfora y una sola metafísica e, incluso, como si ambos

6 Traduoción castellana en HEIDECCER, M. L p proposicion dd fundomento, Ed. del Serbal, Barcelona, 1991, p.89. 
pudieran encontrar un final simple, un cierre definitivo, la lectura derridiana revela su intima complicación.

Al retenerse el ser en su epoché, la historia de la metafísica occidental (su época) tendría como marco definitorio, el haber desplazado su referente propio a una retirada, colocándose de esta manera ella misma en posición trópica respecto del ser. Ya que éste no se entrega en una inmediatez presencial, elude toda posibilidad de un discurso propio acerca de él. Con ello, no sólo se abriría un ámbito en el interior del cual tiene lugar lo metafórico, sino que la metafísica misma supondría un desvío metafórico. Así, el fin de la metafísica, y el consiguiente fin de la metáfora, vendría marcado por la retirada de aquel desvío, por un doble movimiento de retirada, retirada de la retirada del ser. En este punto seguimos literalmente a Derrida:

"Pero como esa retirada de lo metafórico no deja el sitio libre a un discurso de lo propio o de lo literal, aquella tendrá a la vez el sentido del re-pliegue, de lo que se retira como una ola en la playa, de un re-torno, de la repetición que sobrecarga con un trazo suplementario, con una metáfora de más, con un re-trazo de metáfora, un discurso cuyo reborde retórico no es ya determinable según una línea simple $e$ indivisible, según un trazo lineal $e$ indescomponible. Este trazo tiene la multiplicidad interna, la estructura plegada-replegada de un re-trazo. La retirada de la metáfora da lugar a una generalización abismal de lo metafórico metáfora de metáfora en los dos sentidos-que ensancha los bordes o que más bien los invagina» ${ }^{7}$

El final y la continuación sin límite, el corte y la vuelta, el giro suplementario, están complicados en el trazo, en el guión. El final de la metáfora y de la metafísica se complica multiplicando sus pliegues, abismando su salida interna. No se puede salir del guión, del tropo ${ }^{8}$, todos estamos complicados en su movimiento. Este es

\footnotetext{
7 "La retirad de la metufore", p.58.

B tropo. (del lat "tropus", gr. "tropos", vuelta, melodía de "trepo", dar vuelta, guiar; (...)) ). MARIA MOLINER. Diccionerio de uso6 del espaniol, voz "tropo". El subrayado es nuestro.
} 
el "drama" (dice Derrida): Por más que quisiéramos salir de nuestro vehículo para describirlo, hablar "propiamente" de la metáfora, ésta nos sobrepasaría, nos pasaria y nos haría hablar desplazados: metáfora de metáfora ( Todo enunciado a propósito de cualquier cosa que pase, incluida la metáfora, se habrá producido no sin metáfora» ${ }^{9}$ ).

¿Cómo pensar ya el fin violento, la súbita discontinuidad, si no es, en un mismo trazo, como continuidad sin fin?. Las dos muertes de la metáfora, los dos trayectos de su auto-destrucción, la muerte de la metáfora y, en una misma tirada, la muerte de la filosofía ${ }^{10}$ y la muerte misma en y desde la filosofía. ¿Cómo pensarlo si no es desde el interior de la metáfora, si no es filosofando también, si no es, en un mismo gesto, guiando y dejándose guiar por la metáfora?.

Hay que arreglárselas para pensar el final sin final, re-pliegue $y$, en un mismo giro, el final total, sin resto ni revelaciones, "apocalipsis sin apocalipsis"1]

A través del texto de Derrida queremos recorrer, si cabe de una forma "relentizada", aquella complicación que pasa por la metáfora $y$ el fin anunciado, entrar en un intrincado laberinto en el que, acaso, resuena el mugido atroz de minotauro.

Con esta actitud seguimos la guía, el hilo, de un cierto tono que desde el principio acompaña a los escritos que tratamos, complicación tímbrica que se deja pensar ahora en el guión, en el trazo, en el trazado de la línea de apertura, ganancia de cuanto "hay" (es gibt), trazo, Riss, trait y, en un mismo movimiento, también, final anunciado y violento. Adoptamos, se quiera o no, un tono apocalíptico ( Entre los numerosos rasgos que caracterizan un escrito de tipo apocalíptico, aislemos provisionalmente la predicción y la

\footnotetext{
9 "La retrada de la metafora", p.37.

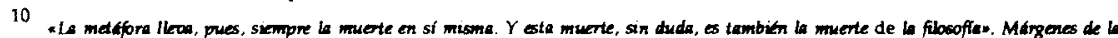
filosofia, op. ot p.310. Hemos modificado algo la traducaón al castellaro. Ver Marges de ia philosophie, Ed. de Minuit, Pars, 1972 , p.323.

11 Vet DERRIDA, J., D'un ton apocalyptique adopté naguitre en philosophic, Gallilee, Parsis, 1983, p.95. Todos los párrafos de esta obra reproducidos aquí son traducción nuestra.
} 
predicación escatológica» ${ }^{12}$ ) complicando con ello hasta el extremo el fin mismo: “cuando hay dos muertes, el problema de la muerte es infinitamente complicado" ${ }^{13}$.

\section{La catástrofe metafórica}

Derrida señala en "Le retrait de la métaphore" los caracteres de una operación llevada a cabo en el cuerpo de escritura heideggeriano, operación que él mismo pone en práctica como un "cuerpo a cuerpo" textual en la frase que titula su artículo (La retirada de la metáfora). Tal operación tendría, entre otros, el efecto inmediato de sacar sus enunciados sobre la metáfora fuera de la disyunción literal/figurado, haciéndoles de esta forma resistentes a una lectura metafísica y trastocando con ello el orden interno por el que ésta articula tales disyunciones.

Para Derrida, el guión (o guiones) que une los enunciados de Heidegger acerca de la metáfora, con el gesto escritural que retira el tema hacia unos pequeños lugares dentro de su "último" pensamiento, juntamente con sus explícitas negaciones de metaforicidad allí donde su texto parece hacerse más metafórico (ejemplo: "casa del ser", "palabras como flores", etc.), pasa por la comprensión de ese movimiento catastrófico que consiste en lo siguiente:

«Se trata siempre de esos momentos típicos en los que, al recurrir a fórmulas que se tendría la tentación de entender como metáforas, Heidegger precisa que no lo son, y lanza la sospecha sobre lo que creemos pensar como cosa segura y clara bajo aquella palabra (...) "casa del ser" no actuaría, en este contexto, a la manera de una metáfora en el sentido corriente, usual, es decir, literal de la metáfora, si es que lo hay. Este sentido corriente y cursivo -que entiendo también en el sentido de la dirección- trasladaria un predicado familiar ( $y$ aquí nada es más familiar, familiarizado, conocido, doméstico, y económico, suele creerse, que la casa) hacia un sujeto menos familiar, más alejado, unheimlich, que se trataría 
de apropiárselo mejor, de conocerlo, de comprenderlo, y que se designaria asi mediante el desvio indirecto por lo más próximo, la casa. Pero lo que pasa aquí con la quasi metáfora de la casa del ser, y lo que pasa por alto a la metáfora en su dirección cursiva, es que el ser dejaría o prometería dejar pensar, a partir de su retirada misma, la casa o el hábitat." ${ }^{14}$

Aquella frase de Heidegger se refiere al lenguaje (Sprache) y enuncia algo acerca del ser (que el lenguaje es la casa del ser); a partir de la inversión catastrófica ya no puede decirse de ella que sea una metáfora o que no lo sea, es un enunciado final; con él queda expresado de una manera ni literal ni metafórica la condición de toda metaforicidad: no se trata de una simple inversión del sentido trópico, sino más bien de un desalojo por sobreabundancia. Allí donde la metáfora se excede y sobrepasa -fin de trayecto, extremo de un guión entre la metafísica y el relevo de la metáforano es ya el sentido metafórico quien, mediante un movimiento de inversión direccional, va a parar a lo que se pretendía sentido propio, sino que toda "propiedad" de sentido (tanto de lo propio como de lo "literalmente metafórico") queda trastocada en el doble trazo de ese trayecto, en la repetición de su trazado: invaginación, pliegue del extremo exterior sobre el interior, doblez en el extremo, inversión y abismamiento del (de los) sentido(s). Aquello que nos parecía más familiar queda ahora extrañado por ese movimiento implícito a la catástrofe metafórica, desfondamiento que conmueve los cimientos de la propiedad familiar.

Ahora la frase no funciona ni como metafórica ni como literal, resistiendo, entonces, a esa disyuntiva y a sus mutuas negaciones («Siempre una metáfora más en el momento en que la metáfora se retira ensanchando sus limites: ${ }^{15}$ ).

Derrida aplica rigurosamente esa operación a su propia frase directriz (frase que jalona la dirección de un movimiento catastrófi-

14 DERRIDA, J., "Le retirada de le metafora" op. at. Pp. 61, 62
15 "La retirada de la metufore", op. at. p.64. 
co del que no puede escapar ni la metáfora ni cualquier enunciado pretendidamente literal sobre ella):

"si se pretendiese que retirada-de se entendiera como una metáfora, se trataría de una metáfora curiosa, trastornadora, se diría casi catastrófica, catastrópica: tendría como objetivo enunciar algo nuevo, todavía inaudito, acerca del vehiculo y no acerca del aparente tema del tropo. Retirada-del-ser-o-de-lametáfora estaría en vias de permitirnos pensar menos el ser o la metáfora que el ser o la metáfora de la retirada, en vías de permitirnos pensar la vía y el vehículo, o su abrirse-paso.» ${ }^{16}$

Ahora la vía y el vehículo -el trayecto de un guión y el guión mismo, su apelación a seguir con él el sentido de la marcha, tropo, guía que dirige como una llamada, "ven", marca a seguir, aquí metáfora de la metáfora- todo ello está en vías de ser pensado a partir de aquella complicación que es la retirada (retrait), juego interno y violento al lenguaje que precisa en castellano una explicación excesiva, antieconómica, que hace de él un término resistente a la traducción y traducción él mismo que exige ahora, también, ser traducido: la palabra francesa retrait, retirada, encierra en su interior escritural una duplicación -re-, una marca que, como en castellano, trae consigo una repetición, un regreso, la vuelta de algo. ¿Qué es ese algo que vuelve? un trazo (trait), guión, rasgo. El re-trait es, entonces, una retirada y una reescritura, el término que escribe, y en cierta forma describe, el juego de una economia en la que ambas se complican, repetición y discontinuidad, la suspensión que se va, que se oculta, y la plusvalía de una ganancia que aparece, de un desvelamiento: repetición que borra toda posibilidad de origen inmaculado, repetición de repetición y, sin embargo,

16

"La retirada de la metifora", op. at. p.60 
origen como trazo que abre (Aufriss ${ }^{17}$ heideggeriano), la retirada y la retirada de la retirada.

La palabra re-trait, dice Derrida, no es demasiado abusiva para traducir Entziehung. Por otra parte, condensa en ella el cruce de dos familias de términos en el texto de Martin Heidegger cuyo parentesco se descubre ahora en "La retirada de la metáfora": Reissen (trazar) y Ziehen (retirar). "Lo que hay es el trazo", pero éste está en retirada, es la retirada misma, esto es, no es nada, un trazo que borra y la borradura misina del trazo. Asume el término derridiano, por tanto, la catástrofe en su máxima extensión semántica.

Partiendo ya de la inversión catastrófica que en la frase (enuncio sin traducir) "Le retrait de la métaphore" diría más acerca del vehículo que del tema "metáfora", más acerca de la metáfora y el ser de la retirada que de la retirada del ser o de la metáfora en sí misma, se nos permite enfilar el horizonte, o el plano de fondo que hemos venido preparando:

«Precipitando mi conclusión en este tercer y último rasgo, quisiera ahora llegar no a la última palabra, sino a esa misma palabra plural rasgo (trait). Y no llegar sino volver a ella. No a la retirada de la metáfora sino a lo que podría en principio parecer la metáfora de la retirada. ¿No habria en última instancia, detrás de todo este discurso, sosteniéndolo más o menos discretamente, retiradamente (en retrait), una metáfora de la retirada que autorizaria a hablar de la diferencia ontológica $y$, a partir de ésta, de la retirada de la metáfora?" ${ }^{18}$

1.- La retirada-de es un movimiento inscrito irremisiblemente en la metáfora y que, de alguna manera le resiste y la posibilita, pone en cuestión toda la estructura de lo metafórico.

\footnotetext{
17 La palabra alemana es taducda por Dernda como entame y el traductor del articulo al castellano, el profesor Patricio Penalver traduce a su vez por "encentadura". En este contunuo trasiego de una lengua a otra, posiblemente, se pierde, por una parte, id introducción en la palabra alemana del Riss, trazo, corte, rasgo, gesto que Derrida recupera en la economsa del retreit, y, por otra ia sonondad fambar gue tiene para el hablante frances la palabra entame y que desgraciadamente pierde la castellana, casi en desuso. "encentadura". No obstante cremos que es la mejor forma de taduar este intraduable movimiento: vencentar. Princapia uno cose de las que se comen o consumen, contando el primer troxe de ella (...). Cortar o mu tiler un miembro. Encentarse. Empaar a liagarse una parte del cuerpo por estar whe tho tiempo acastedo sobre elle. (MARLA MOLINER Dxionario de uso del español).

18

"la retirada de la metufora", op. at. p.65
} 
2.- Tal retirada-de contiene una complicación escritural, una reescritura como movimiento de repetición y, a la vez, como apertura, trazo, corte abriente.

3.- Si estuviéramos en otro contexto y si en éste se pusieran las salvedades pertinentes (pueden servir unas comillas) a palabras como "ontología" o "lengua", diríamos que el alcance (catastrófico) de la metáfora (la metáfora de la retirada) no es sólo "lingüístico" sino "ontológico", aunque debe quedar de inmediato entendido que tal alcance no implica la reducción ni de lo ontológico a lo lingüístico ni a la inversa, sino, más bien, que la re-tirada ${ }^{19}$ como vehículo se convierte en la posibilidad de poder pensar ambos dominios, e incluso, en la condición de su posibilidad misma.

4.- Con ello llegamos a complicaciones "esenciales" que implican a la "esencia" misma. Entre el ser y la nada, y en el "entre" de todas las oposiciones de valor que construyen la arquitectura metafísica. Aquí el trazo (los trazos) entre ambos extremos posibilita tales distinciones $y$, a la vez las complica, borra todo halo de pureza y de estanqueidad en sus polos. Hace a los extremos mutuamente cómplices, sin embargo, el trazo no pertenece a ninguno de los dos:

"Asi, pues, el trazo (trait) no es nada. La encentadura del Aufriss no es ni pasiva ni activa, ni una ni múltiple, ni sujeto ni predicado, no separa más de lo que une. Todas las oposiciones de valor tienen su posibilidad en la diferencia, en el entre de su separación que concilia tanto como desmarca. (...)

La retirada (retrait) no es ni una cosa, ni un ente, ni un sentido. Se retira del ser del ente como tal y del lenguaje, sin que esté, ni sea dicho, en otra parte; encenta la diferencia ontológica misma. ${ }^{20}$

5.- El trazo (trait) de la retirada (retrait) de la metáfora economiza un cruce, posibilita, guía y condensa el desplazamiento en el

\footnotetext{
19 Habria que ver también en esa "tirada" que se escribe junto al guion, una "tirada" de dados en complicacion con aquella línea
que se traza, "tirada" como una raya, rayar, hacer surcos, grabar.

20 "La retirada de la metsfora", op. cit. pp.73 y 74.
} 
interior de aquella palabra (Ereignis) que cruza; como apunta Derrida:

"cuya entera familia (ereignen eigen, eigens, enteignen) se cruza, de forma cada vez más densa, en los últimos textos de Heidegger, con los temas de lo propio, la propiedad, la apropiación, o la des-propiación, por una parte, y con el de la luz, el claro, el ojo, por tra parte (Heidegger dice que sobrentiende Er-augnis en Ereignis) y finalmente, en su uso corriente, con lo que viene como acontecimiento" ${ }^{21}$

Lo propio, lo visual y el advenimiento, lo que acontece, lo que pasa, no pueden pasar sin la metáfora. La retirada (del ser) que acontece como palabra apropiada, que abre a su vez la época de la metafísica y, por tanto, de la metáfora, así como el final doblado de ambas, tiene su condición en aquel re-pliegue del trazo: él mismo se encuentra velado, retirado $-\ll E l$ trazo de la encentadura está pues velado, retirado, pero es también el trazo que reúne y separa a la vez el velamiento y el desvelamiento, la retirada y la retirada de la retirada. ${ }^{22}$ - Una veladura que exige su apocalipsis.

\section{El Apocalipsis.}

Lo que venimos hasta aqui remitiendo a la metáfora y su relevo debe ahora, por medio del efecto de su catástrofe interna, recaer sobre la re-tirada, sobre el fin sin más, la retirada general que actúa en la irrupción de lo que "hay", sobrecargando este acontecimiento con la repetición, la reinscripción de una escritura general $y$, así, con la autodestrucción en y del origen mismo, con la ausencia manifiesta y la manifestación de la ausencia como condición que posibilita todo acontecimiento. El guión, su extraña llamada de vigilia, de vigilante que requiere un relevo, se complica en (el) extremo:

«El acontecimiento de ese "Ven" precede y llama al acontecimien-

to. Seria eso a partir de lo cual hay acontecimiento, el venir, el

21 "La retirada de la metdfora", op. at. p.52
22 "La retireda de la metofora", op. cit. p.71. 
por-venir del acontecimiento, que no se puede pensar bajo la categoría dada de acontecimiento" ${ }^{23}$.

Aquella apelación seductora que reúne toda la confusión y la extrañeza tímbrica de lo que se adapta a cualquier tono, recoge para Derrida toda la energía del envío apocalíptico (remite, en última instancia, confiesa el autor, al Apocalipsis de Juan ${ }^{24}$, envío con destino no asegurado y con remitente continuamente remitido, reenviado, relevado) y guarda la misma estructura catastrófica que la retirada:

«No se sabe ya muy bien quien presta su voz y su tono al otro en el Apocalipsis, no se sabe ya muy bien quien se dirige a quien. Pero por una inversión catastrófica, aquí más necesaria que nunca, se puede también pensar esto: desde que no se sabe ya quien habla $o$ quien escribe, el texto se hace apocalíptico. Y si los envios remiten siempre a ot ros envios sin destino decidible, el destino que queda por venir, entonces esta estructura totalmente angélica, la del apocalipsis de Juan ¿no es también la de toda escena de escritura en general? ${ }^{25}$.

Este guión no se dejaría sin más colocar ahora en un plano trascendental, sería, más bien, "quasi-trascendental" -como no se dejaría nombrar de una forma metafórica ni literal, sino "quasimetafórica"-. Con ello no sale fuera de lo empírico, es más, el corte entre lo empírico y lo trascendental quedaría también conmovido por aquella apelación relevante.

La retirada implícita en la presentación repetitiva, reinscripción de la metáfora, metáfora misma de la re-tirada, metáfora del fin, continuo reenvío, no puede, así, eludir un cierto tono. El corte de un velo que se retira marcando, remarcando, el espacio diferencial entre el velamiento y desvelamiento:

«La lengua griega se muestra aqui hospitalaria al gala hebreo (...)

Parece decir en efecto el apokalupsis, el descubrimiento, el

23

24

25 
desvelamiento, el velo levantado sobre la cosa (...). En ningún lugar la palabra apocalypse, concluye el traductor ${ }^{26}$ refiriéndose aqui tanto al griego como al hebreo, tiene el sentido que ha acabado por tomar en francés y en otras lenguas: catástrofe temible (...). Asi el Apocalipsis es esencialmente una contemplación (...), o una inspiración a la vista, al descubrimiento de YHWH (...) ${ }^{27}$

La "re-tirada de" acontece como un desvelamiento, esa metáfora catastrófica nos ha guiado hasta el lugar (o la falta de lugar) en el que el fin de la metáfora (o el fin sin más) se avecina, en el que aquello que viene a ser -por llamarlo de un modo en el que el "venir a ser" tiene una connotación que remite a alguna forma de simulacro- llega a un cierto espacio del desvelamiento. Aquello que estaba velado, retirado, es puesto al desnudo. Pero lo que esta economía permite (también en el marco de la limitación en que tal palabra toma su significado) a su vez, pensar es que todo cuanto llega (recuérdese la ley de todo transporte, vía, vehículo), todo cuanto es enviado, no tiene de antemano su destino seguro, requiere siempre una cierta sorpresa, la gratuidad de toda donación.

\section{El corte final}

Hemos apuntado una trayectoria a seguir -no olvidemos que este trabajo es tan sólo un "guión"- pero nuestro empeño quiere, más bien, fijarse en la pertinencia aniquiladora que trae consigo aquel trazo cortante, que (nos) "da un corte", queremos buscar ya un final para este guión, un final súbito $y$, por tanto, un final sin final, sin conclusión, porque en el principio estaba ya su final doblado. La autodestrucción, la remitencia sin fin articula una estructura invaginada, como un hueco, que ahora se nos hace innombrable (ni metafórica ni literalmente), a lo más, señalable por un guión (por un trazo, también por una $X$ ). Lo que sí cabe decir

\footnotetext{
26 Dernda se retiere al Apocalupsis de fuan en la traducsión que hizo del grego André Chouraqui. Ver "DYun ton ..." p.12

27 Otra complicación que atraviesa el texto de Derrida, esta vez entre lo más cercano y famular y lo más alejado y extr afo, lo otro, entre lo griego y lo hebreo, entre el "pensamuento del ser" y la "escritura del otro. Movimientos todos ellos que por razones de economid vamos a dejar pasar aquS. "D'un ton." op. di. pp. 12, 14 .
} 
es que tal clausura no tiene lugar (apocalipsis sin apocalipsis), o lo que es lo mismo, puede operarse en cualquier parte, hace del lugar y del "tener lugar" (también del "dar lugar") un movimiento complicado con la traslación y el transporte, el río ${ }^{28}$ : «Interrumpo aquí arbitrariamente mi lectura, la corto de un trazo en el momento en que nos iba a llevar al Ge-stell de la Gestalt en el ensamblamiento (Gefuige) de la cual der Riss sich fügt ${ }^{29}$. Asi anuncia Derrida el final de su conferencia, última página de "Le retrait de la métaphore".

¿Cómo declarar la pertinencia de este corte dentro del desarrollo del movimiento del texto sobre la metáfora? ¿Puede ese "corte arbitrario" ser impertinente para pensar la metáfora? ¿De qué modo se insertaría, si es que es posible hacerlo, la ley del corte, o mejor su falta de ley, su rigurosa falta de rigor, en la economía de plusvalía puesta también en marcha por el trazo, por el "re-trazo"? ¿Puede el lugar en que la lectura queda violentamente interrumpida, lugar de la conclusión, organizar una cierta topología, tropología?.

Tan sólo, llegados a este espacio de conclusión, apocalipsis del apocalipsis, cabría decir que el lugar del final no expresa ni articula un movimiento capaz de organizar una jerarquía de lugares, algo así como una topografía divisoria entre lo conclusivo y lo no conclusivo, entre lo relevante y lo irrelevante: enunciar la falta de conclusión enuncia a la vez la falta de señales irrelevantes. Todo puede ser conclusivo. Esa vigilancia que requiere el texto, también el del Apocalipsis, estado de víspera, le es inherente al final mismo, lo que no se deja coger por cualquier escato-teo-logía.

Con todo ésto el guión nos ha llevado a hacernos cargo de un fin complicado, lo que en principio parecía una guía para pensar la metáfora nos ha puesto en camino de pensar el final. De una forma catastrófica y desviada hemos querido dar un lugar a la reflexión de aquello que no ha tenido lugar y que, precisamente,

\footnotetext{
28

Recuérdese aquif el "guion" de la peifcula "Apocatypois naw", aquel no que conduce al final en al que la muerte deja de tener una "causa" para ser ella misma un efecto originario, incontrolable y contagiosa. Tambien, "Dun ton..", p. 95.

29 "La retirada de la methfora", op. ct. p. 73
} 
posibilita el "dar lugar". "Lo que aún no ha tenido lugar" vuelve como llamada, "ven", reenvio, haciendo posible que la mirada hacia las cosas, descubra en ellas su irrupción violenta, recortadas sobre el escenario vacio en el que se producen los simulacros ${ }^{30}$. Posibilidad y perversión trenzada de cualquier legalidad de lo propio.

Acaso, aquella forma abrupta de terminar la conferencia pronunciada por Derrida deba ser el gesto indicador de lo radical del fin que se reenvía, del "no va más" sin resto que, sin embargo, pretendemos abrir paso en nuestra escritura. De cualquier modo, de aquel reenvio sólo puede hablarse metafóricamente, mejor, quasimetafóricamente. Para empezar (para acabar) puede dársele un nombre que condensa el tráfico de sus múltiples influencias, un nombre catastrófico, catacrético: muerte.

30 En el "Difibgo a cere del habla", publicado en HEIDECGER, M De camino al heble, op. ot. p.98, se describe la palabra "gesto"

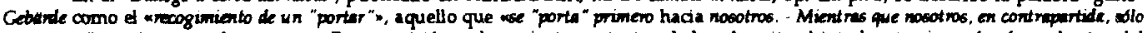
"portamos" nuestra parte al acrentrom. Esta precision se hace, justamente, tras haber descrito el interlocutor japonés cormo el actor del teatro No hace surgir las cosas a traves de "gestos" que se recortan en un "escenario vacio". 